\title{
A CONFIGURAÇÃO DA NARRATIVA HISTORIOGRÁFICA NA ESCRITA DE EDUARDO GALEANO
}

\section{THE CONFIGURATION OF THE HISTORIOGRAPHICAL NARRATIVE IN THE WRITING OF EDUARDO GALEANO}

\author{
Heloisa Helena Ribeiro Miranda, \\ Instituto Federal de Rondônia, Vilhena, Rondônia, Brasil \\ heloisamiranda@hotmail.com \\ Célia Maria Domingues da Rocha Reis, \\ Universidade Federal de Mato Grosso, Cuiabá, Mato Grosso, Brasil \\ celiadr@uol.com.br \\ João Paulo Rodrigues \\ Universidade Federal de Mato Grosso, Cuiabá, Mato Grosso, Brasil \\ perfejp@yahoo.com.br
}

\begin{abstract}
Resumo: Neste artigo objetivamos demonstrar como Eduardo Galeano configura sua narrativa, adequando-a as exigências próprias da historiografia. Procedemos a uma análise formal e de conteúdo, investigando a maneira como o escritor uruguaio, em seu texto "La reconquista de Brasil", da obra Memoria del fuego (2010), consegue atender a imperativos do fazer historiográfico, como a datação dos fatos, o registro documental, a crítica das fontes, os agentes históricos e a objetividade da linguagem. Os resultados da análise revelaram que Galeano compõe outra perspectiva narratológica para abordar o Golpe Militar de 1964, no Brasil. Nesse sentido, concluímos que a forma como Galeano compõe o seu texto pode ser vista como uma narrativa historiográfica que não se afasta da Teoria da Literatura, mas agrega sua metodologia.
\end{abstract}

Palavras-chave: Teoria da História; Teoria da Literatura; Narrativa; Eduardo Galeano

\begin{abstract}
In this article we aim to demonstrate how Eduardo Galeano configures his narrative, adapting it to the demands of historiography. We proceed to a formal and content analysis, investigating the way the Uruguayan writer, in his text "La reconquista de Brasil", from the work Memoria del fuego (2010), can meet the imperatives of historiographic making, such as the dating of facts, the documentary register, the critique of the sources, the historical agents and the objectivity of the language. The results of the analysis revealed that Galeano composes another narrative perspective to approach the 1964 Military Coup in Brazil. In this sense, we conclude that the way Galeano composes his text can be seen as a historiographical narrative that does not deviate from the theory of literature, but adds its methodology.
\end{abstract}

Keywords: Theory of History; Theory of Literature; Narrative; Eduardo Galeano 


\section{A narrativa como forma de humanização do tempo físico}

A narrativa é o gênero ao qual o homem confia o conteúdo de sua existência, em formas orais ou escritas, estruturando-se em fábulas, contos, novelas, romances, epopeias, dramas, tragédias etc. "Não há em parte alguma povo algum sem narrativas; todas as classes; todos os grupos humanos têm suas narrativas", diz Barthes et al (2013, p. 19). Para Maurice Blanchot (2005), a narrativa realiza a ação simultânea de falar sobre o acontecimento, ao mesmo tempo em que se produz, autogestação possível porque detém o ponto e o plano no qual a realidade narrativa se manifesta. Ressalta-se que, embora o caráter axiomático da narrativa seja a travessia do conteúdo, expresso em estruturas diversas, não há como desconsiderar a experiência temporal e espacial que nela reside, uma vez que a narrativa é tempo e espaço conjugados e, por isso, é o lugar onde tais dimensões se realizam.

Então, além de carrear as informações sobre o mundo e seus habitantes, a narrativa é o meio pelo qual o tempo físico se humaniza, de acordo com Ricoeur: "o tempo torna-se tempo humano, na medida em que ele se articula de modo narrativo; a narrativa atinge sua significação plena, quando ela se torna uma condição da existência temporal" (1995, p. 22). Para tanto, o filósofo parte das aporias filosóficas sobre o tempo de Santo Agostinho, a partir da relação fenomenológica da experiência humana do tempo, conjugada à análise realizada por Aristóteles entre mŷthos e mimesis ${ }^{1}$ (RICOEUR, 1995).

Ricoeur parte da perspectiva psicológica e dicotômica de Santo Agostinho no que diz respeito à intentio e à distentio animi. A intentio animi é o ato de atenção a uma das dimensões do tempo presente (presente do pretérito, presente do presente e presente do futuro). Para explicá-la, o filósofo romano traz, como exemplo, o instante da recitação de um poema memorizado. No ato da fala do poema, em virtude da intentio de dizer, há uma dilatação da memória, estando o poema memorizado, relacionada aos versos, os quais já foram recitados. Porque os versos já foram enunciados, eles se constituem de um passado do tempo presente; no entanto, ainda há a "expectativa" ou "tensão" dos versos, que estão por vir, ou seja, o presente do futuro. A ansiedade existente, no espírito, de quem recita o poema, origina essa expectativa, que ocasiona a distentio animi, suscitada a partir de intenções de prolongamento do fenômeno mnemônico.

Para Santo Agostinho, o tempo está relacionado à subjetividade e, esta, à eternidade, não havendo uma fenomenologia do tempo na filosofia agostiniana, mas uma composição argumentativa. Tal composição advém de uma questão ontológica: "O que é, com efeito, o tempo? - Quid est enim tempus?", localizada no Livro XI das Confissões, capítulo 14, item 17. Agostinho adota uma percepção cética do não-ser do tempo, concatenada à estrutura da linguagem, segundo Ricoeur: "Se tomamos o tempo enquanto ser (será, foi, é), como nasce o uso dessa certeza do ser do tempo?” (1995, p. 23). Há na indagação uma relação paradoxal entre o ser (experiência do sujeito) e o não-ser (estrutura da linguagem). Tal antagonismo é engendrado, na filosofia agostiniana, por um traço do ser e do não-ser, no instante em que, valendo-se da memória, o sujeito da enunciação aproxima passado e futuro, com o intuito de realizar uma mediação do presente: "só é presente o ano em curso; e, no ano, o mês; no mês, o dia; no dia, a hora: e esta hora única, ela própria, corre em partículas fugidias: tudo que fugiu é passado, tudo que lhe resta é futuro" (AGOSTINHO, 1996, p. 337). Nessa perspectiva, o presente é um elemento temporal que não pode ser dividido, ele não comporta uma espacialidade, não pode prolongar-se.

Ao serem relacionados ao presente, passado e futuro ganham qualidade - adjetivos os quais estão prestes a serem considerados como seres: "não o passado e o futuro como tais, mas qualidades temporais que podem existir no presente sem que as coisas de que falamos

\footnotetext{
${ }^{1}$ Mŷthos e mímesis serão tratados adiante.
} 
quando as narramos ou as predizemos ainda existam ou já existam (RICOEUR, 1995, p. 21)". Após compreender como se organizam a intentio e a distentio animi em Santo Agostinho, Ricoeur as relaciona com as reflexões de Aristóteles, em $A$ Poética, sobre a arte de imitar ações. Ricoeur observa que há inversão da distentio animi no conceito de composição da intriga (mŷthos), uma vez que o ato de compor a representação liga-se ao modo como ela é dinamizada, isto é, o mŷthos apenas pode se realizar devido ao prolongamento do ato enunciatório operado pela linguagem.

\footnotetext{
De um lado, encontrei no conceito de tessitura da intriga (mŷthos) a réplica invertida da distentio animi de Santo Agostinho. Agostinho sofre sob a coerção existencial da discordância. É evidente que sou eu, leitor de Agostinho e Aristóteles, quem estabeleço esta relação entre uma experiência vivida em que a discordância dilacera a concordância, e uma atividade eminentemente verbal em que a concordância repara a discordância. Por outro lado, o conceito de atividade mimética (mimese) colocou-me no caminho da segunda problemática, a da imitação criadora da experiência temporal viva pelo desvio da intriga. (RICOEUR, 1995, p. 55).
}

Na perspectiva do filósofo francês, a discordância é formulada com base na teoria do tempo, de Agostinho, acerca de seu conceito de distentio animi (prolongamento), enquanto que a concordância é apontada como aquilo que caracteriza a operação de pôr em intriga as ações por meio da linguagem. Por esse motivo, Ricoeur percebe que há um triunfo da concordância sobre a discordância, advinda de um acordo entre as ações e sua temporalidade. Ricoeur pontua, então, que a obra de Aristóteles nada diz sobre a relação existente entre a ação poética e a experiência temporal. Contudo, considera esse silêncio muito produtivo, instaurador de uma distância que oportuniza a investigação das operações entre a experiência vivida e a composição do texto. Segundo Ricoeur, em Aristóteles, o mŷthos corresponde, afinal, ao método de agenciamento dos fatos, em sistema, e que a poética está concatenada como a arte de compor a suspensão temporal desses fatos. Assim, o mŷthos não diz respeito somente à estrutura de composição da intriga, mas liga-se às operações que possibilitam a sua formatação. Ricoeur conclui que "o mŷthos trágico emerge como a solução poética para o paradoxo especulativo do tempo, na própria medida em que a invenção da ordem é introduzida como exclusão de qualquer característica temporal" (1995, p. 68, grifo nosso). Por sua vez, a mímesis diz respeito à capacidade de dar forma à substância, transformando-a em ações poéticas. As ações poéticas compreende ao como se, o qual não é visto por Ricoeur como ficcionalidade, mas como uma possibilidade de construir diferentes métodos de enunciação visando dar conta da voracidade do tempo físico.

\section{Dos limites entre a narrativa histórica e a ficcional}

Limite: eis aqui um exemplo, diria Valéry (1991), de uma das palavras atormentadoras do espírito. Do latim limes, substantivo masculino, é dicionarizado (BECHARA, 2011) como linha cuja característica é estremar espaços próximos. Em uma acepção filosófica, indica o término de uma coisa fora da qual não há existência e, ao mesmo tempo, constitui-se em começo de outra coisa diferente (MARCONDES, 2001). A coisa, para a perspectiva heideggeriana (1992), é responsável por formar uma substância que singulariza a existência de um ser ou de um ente, sendo essa matéria encarregada em dinamizar o ser-no-mundo. Desse modo, para a filosofia, o limite não se configura como uma fronteira entre essencialidades, mas como ponto de finitude e de partida, como fim e começo. Ainda acerca do termo limite, Hannerz (1997), antropólogo sueco, argumenta sobre a contribuição do processo de globalização para a diluição dos espaços demarcatórios da cultura e a composição fluida de suas identidades, afirmando que, "às vezes, o limite é visível, outras vezes não. É 
melhor entendê-lo como um ziguezague ou uma linha pontilhada [...] que nos permite discernir descontinuidades, tanto na dimensão social quanto na cultural" (1997, p. 17).

Os significados mencionados aparentam apresentar um aspecto paradoxal do limite em si mesmo, por um lado, uma luta de composição de fronteiras; por outro, a de sua diluição. É como se a coisa, particular em seu limiar, assentisse à existência de outra, distinta da anterior, mas que carrega em si um traço partilhado. Mesmo que o limite seja estabelecido como meio de organização de sistemas (sociais, científicos, políticos, econômicos, históricos ou culturais), compõe-se em espaços de contato entre múltiplas singularidades. À medida em que há uma fricção nos contatos estabelecidos nos espaços, novas coisas são compostas e, consequentemente, o limite deixa de ser finitude e se converte em infinitas possibilidades.

Para compreender como esse limite, às vezes, não se apresenta de forma tão definida quando falamos de Teoria da História e Teoria da Literatura, procederemos à análise da narrativa de Eduardo Galeano, observando como o método do fazer historiográfico se organiza e se materializa em termos linguísticos e, ao mesmo tempo, dialoga com o fazer literário. Iniciaremos com a abordagem historiográfica, que Galeano demonstra ter em vista quando escreve esta obra. Perceberemos o uso da vertente metódica ou "positivista", a fim de demonstrar como, de fato, o autor se esforça para dar conta de todos os seus imperativos. Veremos também, como a Literatura, com seus jogos de linguagem, é um espaço que consente uma fluidez de extremos, com o intuito de identificar os pontos de contato ou mesmo a solvência de limites entre a História e a Literatura.

$\mathrm{Na}$ introdução à obra $A$ escrita da história, Michel de Certeau faz importante referência a um dito do historiador francês do século XIX, Jules Michelet, no qual este ser refere à escrita da história e à voracidade pela reconstituição do passado a partir do presente, como um caminhar sem tréguas, que, pela força do desejo e "sob as esporas de uma curiosidade ardente, nada poderia deter" (MICHELET apud CERTEAU, 2011, p. 16), narra um mundo morto. Para Michelet, a mortalidade desse mundo se manifesta em sua materialidade pretérita: "no sepulcro habitado pelo historiador não existe senão o vazio" (MICHELET apud CERTEAU, 2011, p. 16). A relação sepulcral com o trabalho historiográfico se dá pela aridez na composição das narrativas, que acolhe fantasmas sob a condição de estarem para sempre calados. Para esse modo de composição, sensivelmente enfatizado pela escola metódica, o historiador deverá cumprir exigências inerentes ao método.

De início, segundo Certeau, a historiografia distingue seu presente de um passado por meio de um corte que "é postulado da interpretação (que se constrói a partir de um presente) e seu objeto (as divisões organizam as representações)" (CERTEAU, 2011, p. 10). No recorte do passado, o historiador deverá realizar uma triagem entre o que pode ser compreendido e o que deve ser olvidado, com o intuito de obter a representação de algo inteligível. Compor um discurso inteligível implica verificar a autenticidade e crítica das fontes, a datação dos vestígios, a notoriedade das personagens e, principalmente, a referencialidade da linguagem. São esses critérios que se manifestam na escrita de Galeano.

\section{4 \\ Juiz de Fora}

\section{La reconquista del Brasil}

Hace casi treinta años, el capitán Olympio Mourao Filho fabricó una conspiración comunista, el Plan Cohen, por orden del presidente Vargas. Ahora el general confiesa que en materia política él es una vaca de uniforme, pero de conspiraciones comunistas sí que entiende.

En el cuartel de Juiz de Fora, alza la espada:

- iArrancaré al Brasil del abismo! — proclama.

Mourao Filho está despierto desde antes del amanecer. Se afeita mientras lee en voz alta el salmo de David que anuncia que todo verdor perecerá. Después, desayuna y felicita a su mujer, por ser esposa de un héroe; 
y a la cabeza de sus tropas emprende la marcha hacia Río de Janeiro.

Los demás generales se le van adhiriendo, uno tras otro. Mientras tanto, avanzan rumbo al Brasil, desde los Estados Unidos, un porta aviones, numerosos aviones, varias naves de guerra y cuatro buques petroleros: es la Operación Brother Sam, para ayudar al alzamiento.

Joao Goulart, perplejo, deja hacer. Su colega Lyndon Johnson envía desde Washington el más cálido reconocimiento a los autores del cuartelazo, aunque Goulart todavía ocupa la presidencia, y el Departamento de Estado anuncia generosos préstamos para el nuevo gobierno. Desde el sur, Leonel Brizola intenta, sin eco, la resistencia. Finalmente, Goulart se marcha al exilio.

Alguna mano del pueblo escribe, en una pared de Río de Janeiro:

- iBasta de intermediarios! ;Lincoln Gordon presidente!

Pero los triunfantes militares eligen al mariscal Castelo Branco, un solemne hombre de armas que carece de sentido del humor y de pescuezo.

(GALEANO, Memoria del fuego III, 115, 141 y 307, 2013, p. 226)

O primeiro passo dado por Galeano, na direção de dar conta do método historiográfico há pouco mencionado, remete à marcação temporal do fato a ser narrado: 1964, data emblemática para a historiografia brasileira, uma vez que nos remete ao ano em que se instaura, pela segunda vez em nosso país, o regime ditatorial. Em relação à marcação do tempo histórico do fato a ser narrado, José Carlos Reis (1996) realiza um debate traçando um símile entre o que seria o tempo físico e o tempo vivido.

O tempo físico se relaciona à axiologia de Platão, Aristóteles, Newton e Einstein, no sentido de que é considerado como uma forma de expressão numérica, em relação à quantidade de posições que um corpo possa a vir ocupar no espaço durante uma trajetória. Nesse modo de compreensão do tempo, o movimento é uma ação reversível e permite que o mesmo ser que foi possa retornar da maneira inicial. Nessa forma de composição temporal há uma régua de homogeneidade, responsável por medir o movimento dos corpos, como se pertencessem a um continuum regular. Na régua, o que serve de base para a contagem precisa dos movimentos são o comportamento dos astros e a velocidade da luz. "Não se fala de atribuições temporais, isto é, não se usa os conceitos de passado/presente e futuro. Não se trata de um tempo vivido, mas neutro, indiferente, natural"' (REIS, 1996, p. 230).

No que concerne ao tempo vivido, Reis traz a reflexão filosófica do tempo marcado pela redução do ser ao nada: Plotino, Santo Agostinho, Bergson, Husserl, Heidegger são citados por relacionarem o tempo à vivência humana. Para a filosofia, embora a consciência do ser se esforce para se preservar como era no início, ela acaba por deixar de ser o que era, tornando-se sempre outra, em virtude do viver e, por essa razão, esquecendo-se de onde viera e de como era; o tempo, então, compõe-se em transformação. "A 'mudança' [...] é um movimento que altera o ser que se move. O ser, enquanto "dura', não é mais o mesmo", (REIS, 1996, p. 231), especificando que não se trata de uma "duração natural [...] contínua, homogênea, regular, mensurável", mas vivida, "humana [...] descontínua, heterogênea, irregular, qualitativa, não numerável” (1996, p. 231).

A dicotomia existente entre o tempo físico e o vivido só pode ser diluída, na dialética entre a natureza do tempo e sua consciência, no instante que eles são transpostos em tempo histórico. Para explicar esse posicionamento, Reis (1996) realiza outra analogia, valendo-se da metáfora da ampulheta. Esclarece-nos que a areia, localizada na parte superior do artefato, corresponde ao tempo humano que, embora pareça sólido, sempre acaba por desabar na parte inferior, em um trans-correr infinito. Reis descreve essa parte superior como sendo o tempo presente; sua essência é não se deixar ser apreendido, visto que ele é sempre devir em relação à parte inferior da ampulheta, que corresponde ao passado, o qual não permanece, posto que ele é o que se foi. No entanto, o pesquisador enfatiza que será necessário controlar a descida da areia, para acompanhar a passagem da humanidade: “[...] Como seria possível? Essa é a problemática do tempo histórico: a do acompanhamento dos homens em suas mudanças e a 
sua descrição e análise" (REIS, 1996, p. 231). Portanto, a problemática do tempo histórico é acompanhar a interminável descida da temporalidade humana, em um esforço desmedido de descrever e analisar suas infinitas amorfias.

O calendário é, portanto, um artifício criado pelo homem, que funciona como uma ponte erguida sobre o abismo entre o tempo natural e o vivido. Ainda que o calendário não naturalize o tempo vivido, de modo paradoxal, ao manter a diferença entre um $e$ outro, edifica uma participação de um no outro, que não os restringe, mas os complementam e, por ser intercessor, irá compor o que Paul Ricoeur (1995) denomina de terceiro tempo, a possibilidade de humanizar o tempo físico por meio da composição da narrativa. Afinal, é a viabilidade de reconfigurar o tempo, na condição de materialidade linguística, que possibilita aos indivíduos percebê-lo em sua dimensão humana. Assim, imperativo para a vida em sociedade, o calendário "[...] sempre é composto por um evento fundador que abre uma nova época, 'ponto-zero' a partir do qual se conta e se data os eventos; depois deste ponto zero percorre-se o tempo em suas direções: do presente ao passado, do passado ao presente." (REIS, 1996, p. 234).

Retomando o texto de Galeano, 1964 pode ser compreendido como um ponto-zero para o calendário da historiografia no Brasil, uma vez que é o marco axial para a consolidação do Golpe Militar. Essa data é o lugar de onde a narrativa parte para descrever esse momento que viera sendo configurado: desde "Hace casi treinta años, el capitán Olympio Mourao Filho fabricó una conspiración comunista, el Plan Cohen, por orden del presidente Vargas" (GALEANO, 2013, p. 226). A linha histórica entre o antes e o depois está delimitada.

Para Reis o historiador vive um paradoxo, uma vez que precisa realizar a manutenção do ser do passado, sendo ele um ser do presente; por esse motivo, ele se confunde com a imagem que ele mesmo construiu e, com a finalidade de erigir imagens do passado, a memória será sua substância mais valiosa.

Seguindo o traçado, nada deslizante, para a escrita metódica ou "positivista" da história, a memória, na condição de registro, jamais poderá ser um traço enigmático, uma imagem borrada, uma vez que é o vestígio quem garante a passagem dos vivos pelo tempo do calendário: "[...] O vestígio para significar, para ser uma informação, para ter sentido, precisa ser datado" (REIS, 1996, p. 238). É nesse sentido de construir uma imagem inteligível, trazendo para a narrativa os vestígios datados possíveis, que Galeano, embora não sendo historiador de formação, produz seu discurso histórico. Afinal, não é esse o discurso exigido ao historiador, ao menos desde o século XIX, pelo método de Charles Seignobos em Introduction aux études historiques (1897)? Não é isto que lhe é cobrado por variadas correntes historiográficas, encontrar a relação entre significante e significado para ajustar a cinta entre o tempo e seus vestígios?

Dar conta dessa exigência, entre o estreitamento do significante e seu referente, é tão claro que, em sua trilogia, Memoria del Fuego, Galeano traz, ao final de cada texto, as fontes consultadas para feitura de sua narrativa. Ele se utiliza tanto das fontes primárias, como jornais e documentos históricos do período, como de fontes secundárias, como verificado na seguinte sequência numérica: “115, 141 e 307”. Desse modo, 115 diz respeito ao texto 1964: visto e condenado pela Casa Branca (1977), de Marcos de Sá Corrêa, no qual o historiador (mais conhecido como jornalista) explica as relações e articulações do governo americano para a construção do estratagema de 1964. Depois, temos 141, que corresponde à obra 1964: A conquista do Estado, Ação política, poder e golpe de classe (1981), de Réne Arnold Dreifuss, historiador uruguaio que se dedicou a compreender o golpe e suas relações de poder. A marcação 307 diz respeito ao texto Memórias: a verdade de um revolucionário (1980), obra autobiográfica de Olympio Mourão Filho, na qual fala a suposta "verdade" dos fatos em relação à Ditatura no Brasil. 
A consulta e a citação das fontes são mais um movimento realizado pelo escritor com a finalidade de configurar essa linguagem que, desviando-se da ficcionalidade, comunique a verdade histórica. Ao trazer o discurso de autoridade para a sua narrativa, Galeano, além de cumprir outro procedimento da empreitada historiográfica, busca apagar os traços de subjetividade de seu discurso. Quanto a esse apagamento, Roland Barthes (2004) argumenta que a historiografia metódica acreditava que bastaria subtrair de seus textos qualquer signo que remetesse ao emissor da mensagem, com a finalidade de construir um discurso objetivo, que se configuraria imparcial. Barthes (2004) ainda explica que essa ilusão não é exclusiva do discurso histórico, lembrando que muitos romancistas, na escola do Realismo, julgaram-se objetivos, pois suprimiram da materialidade linguística os signos supostamente subjetivos.

Embora os signos da referencialidade sejam mais evidentes na narrativa de Galeano, ele não consegue suprimir o traço de subjetividade, uma vez que o tropo da ironia, recurso característico do autor expõe elementos do método "positivista", podendo ser interpretado como um índice dessa subjetividade. No que tange à ironia, Hegel (1999) a compreende como sendo uma linguagem que expressa uma "consciência infeliz" do sujeito que age como se estivesse livre, mas sabe que está preso a uma força que lhe é exterior. Então, compreendemos que, ao se valer dessa marca linguística o narrador se mostra, visto que é a própria "consciência infeliz" que aí se manifesta: "Pero los triunfantes militares eligen al mariscal Castelo Branco, un solemne hombre de armas que carece de sentido del humor y de pescuezo" (GALEANO, 2013, p. 226, grifo nosso).

Outro aspecto importante a ser considerado nessa escrita metódica está ligado ao sujeito da enunciação. Galeano cria um narrador que apresenta os fatos, à maneira do jornalismo. Segundo a vertente barthesiana, toda narrativa estabelece uma relação de homologia entre o narrador, denominado doador, e o leitor, reforçando que é do conhecimento de todos que, na comunicação linguística, o eu e o tu discursivos já estão pressupostos. No que diz respeito a essa homologia, Barthes defende que a problemática não reside em encontrar as marcas linguísticas do narrador e, muito menos, os efeitos que a narração produz no leitor, mas o de descrever o código através do qual narrador e leitor são significados no percurso narrativo.

O narrador de Galeano se utiliza dessa câmera significante ao traçar um paralelo na representação da personagem Mourão Filho: "Mourao Filho está despierto desde antes del amanecer. Se afeita mientras lee en voz alta el salmo de David que anuncia que todo verdor perecerá. Después, desayuna y felicita a su mujer, por ser esposa de un héroe [...]" (GALEANO, 2013, p. 226). Há contiguidade entre a esfera política, de poder público, conferido à personagem em virtude do posto de general do exército brasileiro, à outra esfera, privada, relacionada ao ambiente familiar, que possibilita a abertura da fenda para a produção do signo de leitura.

Outro traço peculiar do discurso histórico positivista é o de narrar fatos ocorridos com grandes personalidades, seus feitos e conquistas. Tal modalidade de memória é denominada por Maurice Halbwachs (2003) como histórica, visto que é responsável pelo resgate da imagem do passado, com a finalidade de preservar lembranças de eventos notáveis da vida nacional. Embora preservar a memória nacional seja um dos objetivos da historiografia do século XIX e começo do XX, é possível já perceber traços da escrita de Galeano que escapam a esse método rumo a uma história a contrapelo, uma vez que embora a memória das personagens estejam presentes, ao realizar a homologia entre público e privado, Galeano enseja contribuir para a desconstrução da memória discursiva das personagens do evento histórico da nação. Nesse intuito, ele incorpora ao enredo sete personalidades importantes na História do Brasil.

Primeiro, ele nos apresenta Olympio Mourão Filho (1900-1972), general mineiro, 
membro da Ação Integralista Brasileira ${ }^{2}$, que participou diretamente de dois episódios relevantes: a configuração do Plano Cohen e o Golpe Militar de 1964. O Plano Cohen correspondeu a um pretenso estudo sistemático das estratégias de incursão comunista, que ganhavam consistência, no Brasil, desde 1935. De acordo com a historiadora Ana Heloísa Molina (1997), tais estudos ofereceram ferramentas para a consolidação do golpe que garantiu a permanência de Getúlio Vargas como chefe de governo, o chamado Estado Novo (19371945).

Getúlio Dornelles Vargas (1882-1954), governante deste "Estado Novo" é a segunda personalidade a compor a narrativa. Ao comandar a Revolução de 1930, depõe o presidente Washington Luís e assume o governo, com um discurso em defesa da família, da tradição e da prosperidade. Segundo a historiadora Heloísa Molina (1997), embora tivesse um governo com ideologias populistas, Vargas teve que se apoiar em algum tipo de autoritarismo, uma vez que o pensamento político da época girava em torno da ordem, da hierarquia e da tradição. Contudo, teriam sido os estudos provenientes do Plano Cohen, no que tange à doutrina fascista, em especial, à solvência do Congresso e à percepção do Estado na condição de entidade soberana, que possibilitaram a dissolução das dicotomias liberdade/autoridade, sociedade/indivíduo e nação/humanidade. Galeano edifica as relações dicotômicas pela referência à ação empreendida pelo general Mourão, "Hace casi treinta años", e ao levante militar de 1964. Em virtude desse movimento, delimita um período histórico e faz o fechamento da cintura na clepsidra.

O vigésimo-quarto presidente de nosso país, João Belchior Marques Goulart (19611964), é o terceiro personagem. A historiadora Lucilia Neves de Almeida Delgado (2009) defende que a notoriedade historiográfica de Goulart é discordante e pouco estudada, restringindo-se a discursos que abordam seu período presidencial e sua deposição pelo golpe militar. Delgado (2009) faz uma crítica à historiografia brasileira, no sentido de que, nas referências feitas por meio da história objetiva sobre o nacional-desenvolvimentismo, Getúlio Vargas e Juscelino Kubitschek são os nomes citados, não ocorrendo "a mesma ênfase [...] em relação a João Goulart, que tem sido relegado a um segundo plano pela produção historiográfica e também pela memória coletiva nacional.” (DELGADO, 2009, p. 125).

A quarta personalidade histórica é o ex-presidente dos Estados Unidos, Lyndon Baines Johnson (1962-1966), que assume o cargo após o assassinato de John Kennedy, em 1962. Camilo Tavares, diretor do premiado documentário $O$ dia que durou 21 anos (2017), faz uma abordagem interessante sobre as articulações e os estratagemas que Lyndon Jhonson utilizou para depor João Goulart do governo brasileiro. Entre elas, a "Operação Brother Sam”, citada na narrativa por Galeano. Assim, o documentário deixa clara a "conspiração" com o propósito de inibir o crescimento do comunismo na América Latina.

Com o objetivo de mostrar como ocorrem tais conexões, Camilo Tavares (2017) reúne documentos expedidos pela Casa Branca e áudios dos presidentes Kennedy e Johnson, em longos diálogos com o Embaixador Lincon Gordon, personagem notória tanto para a história quanto para a narrativa. Nas gravações, ambos falavam sobre a ameaça que pairava sobre todos se, por ventura, o Brasil se tornasse "outra Cuba". Além dos áudios, o documentário também traz entrevistas com pesquisadores brasileiros e americanos e testemunhos de militares, com o objetivo de abordar quais foram as estratégias utilizadas pelo governo americano para compor o enredo do dia 1 de abril de 1964: "Joao Goulart, perplejo, deja hacer. [...] Desde el sur, Leonel Brizola intenta, sin eco, la resistencia. Finalmente,

\footnotetext{
2 AIB foi uma organização política de âmbito nacional inspirada no fascismo italiano, fundada por Plínio Salgado, em 1932, trazendo como ideário básico a defesa de um nacionalismo, definido mais sobre bases culturais que econômicas, e de um corporativismo, visto como esteio da organização do Estado e da sociedade, com o propósito de combater valores liberais e, por conseguinte, rejeitando o socialismo como modo de organização social.
} 
Goulart se marcha al exilio." (GALEANO, 2013, p. 226). Nessa passagem emerge a sexta personagem. Leonel de Moura Brizola (1922-2004), que na época do estratagema, era deputado federal pelo Rio Grande do Sul e foi importante aliado de Goulart, chegando a articular, com os militares legalistas, a chamada Segunda Cadeia da Legalidade. Segundo Abreu (2014), Brizola acreditava na adesão do povo brasileiro à defesa pela democracia, da mesma forma que havia sido em 1961, quando as vitórias em prol do presidencialismo e o plebiscito de 1963 levaram a esquerda a acreditar que bastaria sensibilizar o povo, na luta em favor das reformas, que teria seu apoio.

O derradeiro personagem, Humberto de Alencar Castelo Branco (1900-1967), assume a presidência do Brasil em 15 de abril de 1964. Castelo Branco já estava sendo cotado como líder caso o empreendimento americano tivesse êxito, uma vez que suas relações com Lincon Gordon sempre foram muito próximas "ideologicamente", sendo categórico quanto a não deixar que a "enfermidade" cubana contaminasse o Brasil e, por conseguinte, a América Latina. É essa proximidade entre Castelo Branco e a Casa Branca que o levaram a ser escolhido presidente.

Galeano consegue inserir, em seu curto texto, tantas personalidades e tantos conteúdos históricos, porque se vale de uma escrita aforística, ou seja, ele consegue sintetizar a substância e compor uma forma narrativa compartimentada. Essa percepção se inspira na análise que Hayden White (2010) realiza da escrita de historiadores como Ranke e Michelet, que fizeram uso de aforismos em seu fazer historiográfico. Segundo Souza (2007), o estilo aforístico se constitui de uma composição cujas reflexões emergem condensadas e, por razão de uma certa brevidade, as informações são inacabadas. Quanto ao traço de inacabamento, explica-nos Souza $(2008$, p. 78$)$ o aforismo disponibiliza o pensamento à decifração ou a interpretação do conteúdo que é sempre múltiplo e ressoa para além de seu sistema ou de sua época.

Galeano cria seus personagens com essa proposição concisa. Apresentando-as com alguma característica física, não se prende ao seu detalhamento, mas aos traços éticos e morais que as constituem e, por isso, esse tropo ganha força na estrutura narrativa. É interessante notar que, quando o autor compõe sua sintaxe para realizar a representação de cada personagem, ele se vale sempre de um enunciado de estrutura direta, composto por um sujeto diátesis verbal, o qual "afecta a la diferencia entre los sujetos de las oraciones activas y los de las pasivas, así como a la relación entre estructuras activas y medias, y otros pares similares" (RAE, 2009, p. 638), por verbos transitivos, acompanhados de "complemento directo".

Em relação à semântica do uso de verbos transitivos acompanhados de "complementos directos", a Gramática da Academia Real Espanhola (2009) esclarece que esse modo de organização sintática corresponde à admissão de grupos nominais e orações substantivas. Essa é exatamente a construção sintagmática que encontramos na composição desta narrativa.

No que diz respeito à maneira como os sintagmas dos textos literários são elaborados, Julia Kristeva (2005) recorda-nos que a literatura é produto de um discurso representativo de uma representação do real cuja inteligibilidade lhe foi por muito tempo exigida. Para falar acerca dessa imposição do verossímil, Kristeva principia dissertando sobre os desafios que a ciência da literatura enfrenta para consolidar-se como tal. Entre as adversidades, a literatura se depara com uma antinomia que a define como ciência: a designação de seu campo de exploração e a fixação de seus limites. Tal contradição se intensifica, segundo Kristeva, ao se partir da sensibilidade produzida pela metalinguagem contida na literatura e na arte e a forma como esses discursos são reconhecidos de modo secundário. 
Para Kristeva, há uma condição de impotência entre o "querer-dizer" e o "poder ouvir" uma vez que direcionam um sentido extralinguístico e limitado do signo. Ao se estabelecer um limite à interpretação, essa limitação gera uma relação simbólica de semelhança, o que vem a implicar uma analogia de primeiro grau e uma prática translinguística direcionada pela razão logocêntrica. O verossímil, contido no texto, deve ser compreendido como aquilo que está aquém e além de si mesmo, ou seja, só pode ser percebido por meio de um trabalho intratextual, no qual o "querer-dizer" transcende a intencionalidade e se converte em produção, isto é,

o sentido do verossímil não tem mais objeto fora do discurso, a conexão objetolinguagem não se lhe refere, a problemática do verdadeiro e do falso não the compete. (KRISTEVA, 2005, p. 136).

Um texto condicionado a um sistema retórico, com configuração discursiva embasada em leis de determinada sociedade, em dado período, está emoldurado em um eterno presente na clepsidra, na qual o futuro nunca chega. Nessa forma de composição textual, o eterno presente é a condenação para sua morte, posto que a moldura, nele contida, acabará por direcionar e determinar uma única lente interpretativa. É dessa forma limitadora que vemos Galeano tentar se afastar.

\section{Considerações finais}

Literatura e história apresentam dicotomias ou correspondências, a depender da corrente epistemológica, relações que nos instigam a questionar seus limites. Contudo, parece-nos tautológico o questionamento sobre onde termina a história e começa a literatura. A problemática é ampliada quando se trata de uma produção fundada em ocorrências históricas, como vimos pela obra aqui apresentada, que pode ser considerada literatura pelos recursos artísticos que emprega. Caso seja esse o fato, é necessário indagar sobre o ponto onde o discurso histórico é posto em suspensão e se passa a penetrar na sutileza das tramas da linguagem literária. Ou mesmo, se é interessante investir a atenção nessas dicotomias, quando as partes ensejam garantir o seu espaço na junção e comungar da interdisciplinaridade.

A partir da análise da narrativa de Eduardo Galeano foi possível compreender como o autor se vale do agenciamento dos fatos históricos para a sua composição. A narrativa traz marcas do método do fazer historiográfico, em especial em sua vertente metódica, ao mesmo tempo em que apresenta técnicas da Teoria da Literatura. A simultaneidade nos leva a considerar a questão não pelos limites entre as áreas, se se trata de narrativa ficcional ou historiográfica, uma vez que é possível realizar intersecção entre ambas. É propriamente o diálogo interdisciplinar que acaba por proporcionar uma leitura da escrita da História que não esteja voltada somente para o conhecimento da história, nem pelo esvaziamento de uma obra literária que prime pela preocupação com a forma, mas que permita ao leitor aflorar o prazer sobre o conteúdo que a forma criativamente pode nos oferecer.

\section{Referências}

Abreu. Luciano Annore. Uma segunda legalidade por Jango: Porto Alegre, $1^{\mathrm{o}}$ de Abril de 1964. Oficina do Historiador, Porto Alegre, EDIPUCRS, v. 6, n. 1, 2014, p. 126-144.

Agostinho. Confissões. Livro XI: O homem e o tempo. São Paulo: Nova Cultural, 1996.

Barthes, R.; Todorov, T; Greimas, A. J.; Bremond, C.; Eco, U. Gritti, J.; Morin, V.; Metz,C.; Genette, G. Análise estrutural da Narrativa. Tradução de Maria Zélia Barbosa. Ed. Vozes: 
Rio de Janeiro, 2013.

Barthes, Roland. O rumor da língua. Tradução de Mario Laranjeira. São Paulo: Marins Fontes, 2004.

Bechara, Evanildo. Dicionário da Língua Portuguesa. Rio de Janeiro: Editora Nova Fronteira, 2011.

Blanchot, Maurice. O livro por vir. Tradução de Leyla Perrone-Moisés. São Paulo: Martins Fontes, 2005.

Charles, Victor Langlois; Seignobos, Charles. Introduction aux études historiques (1898). Paris. Éditions Kimé, 1992.

Certeau, Michel de. A escrita da história. Tradução de Maria de Lourdes Menezes. Rio de Janeiro: Florence, 2011.

Corrêa, Marcos Sá. 1964 visto e comentado pela Casa Branca. Porto Alegre: LPM, 1977.

Delgado. Lucilia de Almeida Neves. O Governo João Goulart e o golpe de 1964: memória, história e historiografia. Revista Tempo. $\mathrm{N}^{\mathrm{o}}$ 28, 2009, p 125-143. Disponível em: http://www.scielo.br/pdf/tem/v14n28/a06v1428.pdf . Acesso em: 02 de setembro de 2017.

Dreifuss, René Armand. 1964: A conquista do Estado. Ação política, poder e golpe de classe. Petrópolis: Vozes, 1981.

Galeano, Eduardo. Memoria del fuego III. Madrid: Siglo XXI, 2013.

Hannerz, Ulf. Fluxos, Fronteiras, Híbridos: palavras-chave da antropologia transnacional. Mana, $\quad \mathrm{n}^{\mathrm{o}} \quad 3, \quad 1997, \quad \mathrm{p} \quad$ 7-39. $\quad$ Disponível em http://www.mat.uc.pt/ mat1202/LimitesEDerivadasWord.htm. Acesso em: 20 de outubro de 2016.

Halbawchs, Maurice. A memória coletiva. Tradução de Beatriz Sidou. São Paulo: Centauro, 2003.

Heidegger, Martin. Que é uma coisa?. Tradução de Carlos Morujão. Lisboa: Edições 70, 1992.

Hegel, Friedrich. Filosofia da História. Tradução de Ma Rodrigues e Hans Harden. Brasília: UnB, 1999.

Kristeva, Julia. Introdução a semanálise. Tradução de Lúcia Helena França Ferraz. $2^{\mathrm{a}}$ ed. São Paulo: Perspectiva, 2005.

Marcondes, Danilo. Dicionário de Filosofia. Rio de Janeiro: Jorge Zahar, 2001.

Molina, Ana Heloísa. Fenômeno Getúlio Vargas: Estado, Discurso, Propaganda. História e Ensino. Londrina, v. 3, 1997, p. 95-112.

Mourão Filho, Olympio. Memórias: a verdade de um revolucionário. Porto Alegre: LPM, 
1978.

Real Academia Española y Asociación De Academias Americanas. Nueva gramática de la lengua española. Madri: Editorial Espasa-Calpe, 2009.

Reis, José Carlos. In: Síntese Nova Fase V. O conceito de tempo histórico em Ricoeur, Koselleck e "annales": uma articulação possível. 1996, p. 229-252. Disponível em http://www.faje.edu.br/periodicos/index.php/Sintese/article/view/989/1428. Acesso em: 25 de novembro de 2016.

Ricoeur, Paul. Tempo e Narrativa: configuração do tempo na relato ficcional. Tradução de Marina Appenzeller. Campinas: Papirus, 1995.

Ricoeur, Paul. A memória, a história e o esquecimento. Tradução: Alain François. Campinas: Editora Unicamp, 2014.

Souza. Ana Cristina Augusto. Salvador Allende e o mito da estabilidade. Revista Intellector. Rio de Janeiro. Vol 3, 2007. Disponível em http://www.revistaintellector.cenegri.org.br/ed2007-06/anacristina-2007.pdf. Acesso em: 17 de outubro de 2017.

Tavares, Camilo. O dia que durou 21 anos. O documentário está disponível em https://www.youtube.com/watch?v=RVnf3Ap7guQ. Acesso em: 02 de setembro de 2017.

Valéry, Paul. Variedades. Org. João Alexandre Barbosa. São Paulo: Iluminuras, 1991.

White, Hayden. "Teoria literária e escrita da história”. Estudos Históricos. Rio de Janeiro, vol. 7, n. 13, 1991, p. 21-48. Disponível em: https://pesquisahistoricaurca.files.wordpress.com/2013/10/teoria-literc3a1ria-e-escrita-dahistc3b3ria-hayden-white.pdf. Acessado em: 11 de setembro de 2017.

White, Hayden. Meta-História: A imaginação histórica do século XIX. Tradução de José Laurêncio de Melo. $2^{\circ}$ Ed. São Paulo: Editora da USP, 2010.

Recebido em: 21 de agosto de 2019 Aceito em: 18 de outubro de 2019

Publicado em: Dezembro de 2019 